\title{
Memória e ficção na correspondência do escritor João Antônio
}

\section{Ana Maria Domingues de Oliveira Telma Maciel da Silva}

\begin{abstract}
Resumo O escritor João Antônio sempre fez questão de, em entrevistas ou textos autobiográficos, aliar sua produção literária à sua história de vida. Este é também um aspecto encontrado em sua correspondência trocada com o amigo de longa data Jácomo Mandatto. São mais de três décadas de troca de cartas, cujo montante acaba por configurar-se quase como um livro de memórias. Palavras-chave João Antônio; cartas, literatura brasileira.
\end{abstract}

Abstract Either in interviews or biographical texts, the writer João Antônio always wanted to associate his literary production with his life history. This is also an aspect found in the correspondence exchanged between João Antonio and his old friend Jácomo Mandatto. It lasted more than three decades and its amount represents almost a memoir book. Keywords João Antônio; letters; Brazilian literature. 
Quando eu morrer, meus amigos de fé herdarão minhas cartas. Tomara fiquem ricos.

[João Antônio]

Vida e Obra Durante mais de trinta anos de profissão, o escritor João Antônio fez da palavra a sua arma de combate. Refratário às divisões de gênero comumente feitas pelos estudiosos da literatura, produziu textos que chamam a atenção por seu caráter de hibridismo e inovação estética. Deu voz à "ralé", à "arraia miúda", enfim, segundo ele próprio diria, àquela faixa que, a despeito de ser a maioria da população brasileira, só era lembrada quando surrada pela polícia em manifestações reivindicatórias ou estádios de futebol.

Polígrafo, como o definem muitos estudiosos de sua obra, João Antônio construiu uma carreira sólida na imprensa brasileira. Atuou no Jornal do Brasil, O Pasquim, Última Hora, O Estado de S. Paulo, na revista Realidade, assim como na imprensa "nanica", termo cunhado por ele para definir os pequenos órgãos de comunicação que se espalharam pelo país a partir dos anos de 1960.

Desde seu livro de estreia, Malagueta, Perus e Bacanaço (1963), o autor já dava a tônica do que seria a sua produção literária. Ambientes e pessoas de sua infância, adolescência e vida adulta, misturados a personagens de ficção, eis aí um dos principais traços da obra de João Antônio. Em um polêmico manifesto, "Corpoa-corpo com a vida", inserido em Malhação do Judas carioca (1975), ele desafia os escritores brasileiros a falar da realidade do país, ou seja, do futebol, de umbanda, das favelas, dos bordéis, dos meninos de rua etc. Entretanto, defende-se daqueles que o viessem a acusar de panfletário: para ele, o escritor deveria ser um "bandido falando de bandidos" e, assim, eliminado o espaço que separa um do outro, não teríamos um panfleto, ou um retrato, mas a voz do próprio "bandido" sendo a mola propulsora do texto.

Para que esse "corpo-a-corpo" pudesse ser travado com a vida, o contista defendia que os escritores saíssem de suas poltronas e de seus escritórios confortáveis e fossem para a "cena do crime", ou seja, para as ruas, botequins etc. O escritor, contudo, não deveria ser um mero observador dessa realidade nova para ele. Foi, então, marcada com o grifo da realidade que se fez a produção literária e jornalística 
de João Antônio. Em entrevistas, sempre fez questão de associar a sua experiência pessoal com a de muitas de suas personagens, deixando também sempre claro que a matéria observada e vivida precisava ser transfigurada pelo trabalho estético, para se tranformar em literatura.

Essa aderência do autor ao universo narrado determinou a construção de um imaginário que funcionou como uma espécie de faca de dois gumes para a sua produção: ao mesmo tempo em que provocava certa curiosidade no público e na crítica, o que tornava badalados seus livros, também ocasionou análises rasteiras, que levavam em conta apenas os aspectos mais triviais de sua obra, não dando conta de suas inovações formais.

Fizemos essa introdução sobre as concepções literárias de João Antônio porque são fundamentais para o entendimento do objeto de estudo que será apresentado aqui, ou seja, parte de sua correspondência - aliás um dos gêneros textuais mais praticados pelo autor.

Correspondências $\mathrm{O}$ que a leitura da obra de João Antônio permite entrever é que ficção e realidade não são os lados opostos da mesma moeda; ao contrário, em alguns momentos, uma pode servir de reflexo para a outra. Se na produção literária temos a presença marcante de elementos factuais, na escrita de cartas encontramos momentos em que o trabalho linguístico empregado permite que aproximemos tais textos daqueles de natureza ficcional.

Antes de entrarmos propriamente na análise de suas cartas, vamos a uma breve apresentação desses documentos. Trata-se de uma coleção de mensagens epistolares trocadas entre João Antônio e o amigo jornalista Jácomo Mandatto, morador de Itapira, no interior do Estado de São Paulo.

Em 1962, João Antônio era um autor que se preparava para deixar o ineditismo. Seu primeiro livro, depois de ter os originais destruídos por um incêndio' que atingiu a casa de seus pais, teve partes re-escritas e já havia sido aprovado

1 Alguns textos foram destruídos completamente, enquanto outros, por já terem sido publicados em suplementos literários, puderam ser recuperados mais facilmente pelo escritor. Para re-escrever os demais, João Antônio afirma ter recorrido também a amigos, a quem, eventualmente, havia enviado partes do livro.

358 - OLIVEIRA, Ana Maria Domingues de; SILVA, Telma Maciel da. Memória e ficção... 
para publicação por uma das principais editoras daquele momento, a Civilização Brasileira. Nessa época, o escritor enviou "Meninão do caixote" para o concurso de contos organizado pelo Centro Itapirense de Cultura e Arte, presidido por Mandatto.

Premiado com a segunda colocação no certame, João Antônio foi convidado para uma cerimônia que reuniria os vencedores. De início, aceitou o convite, mas depois, por conta de outros compromissos, desculpa-se e acaba por não comparecer à solenidade. É dessa forma que nasce a longa correspondência trocada entre ele e Mandatto, diálogo que, com certos hiatos e também períodos de intensa troca postal, duraria até meados da década de 1990, pouco tempo antes da morte do contista de Leão-de-chácara.

É interessante salientar que a amizade nasce por conta da troca de cartas e não o contrário. João Antônio e Jácomo Mandatto, antes de se encontrarem pessoalmente, correspondem-se por alguns anos. Ao longo da vida, tais encontros foram, certamente, muito menores em quantidade do que o envio de cartas, que somam cerca de trezentas, a maior parte remetida por João Antônio.

Às cartas, juntam-se também centenas de artigos de jornal de e sobre João Antônio acumulados por Mandatto ao longo dos anos em que se correspondeu com o escritor. Vale observar que todo este manancial de documentos foi sendo composto também por conta da correspondência, uma vez que grande parte dele foi enviado pelo próprio ficcionista, a fim de munir o amigo não só de material necessário para que ele divulgasse prontamente a publicação de seus livros, como também para que se tornasse uma espécie de arquivo biográfico.

Em carta de $1^{\circ}$ de outubro de 1980 , João Antônio faz algumas reflexões a respeito dos documentos que enviava a Mandatto e o "nomeia" seu biógrafo oficial: "Como v. vem sendo de uma fidelidade draculesca nestes últimos vinte anos, fica eleito meu biógrafo-ensaísta, etc. precocemente". Não só a correspondência trocada com Mandatto deveria servir de base para essa biografia; cartas a outros de seus destinatários também deveriam ser recolhidas e publicadas.

Vê-se, assim, que João Antônio se relacionava com a sua correspondência de modo muito particular. De um lado, ela é espaço de experimentação linguística, que culmina em um trabalho estético; sob essa perspectiva, algumas das cartas (ou trechos delas) irmanam-se a textos literários de sua lavra. Por outro 
lado, há também a assumida estratégia de preservação da memória e construção de um imaginário, o que acaba por permitir a leitura do conjunto como uma espécie de autobiografia fragmentária, associada às estratégias discursivas do diário íntimo.

Neste ponto, chegamos ao cerne deste trabalho, uma vez que memória e construção literária em João Antônio são questões bastante imbricadas. Como vimos anteriormente, a sua prosa de ficção acolhe fatos e, principalmente, pessoas reais, ganhando um matiz literário não exatamente pela inventividade ficcional, mas sobretudo pelo engenhoso trabalho com as palavras e, ainda, pelo tratamento dado às personagens, que assumem as rédeas da história, como se o escritor por trás delas nem sequer existisse.

A memória construída como literatura O escritor português Virgílio Ferreira, no livro de memórias Conta-Corrente I, afirma: "O meu diário está nas centenas de cartas aos amigos".2 Esta frase, a nosso ver, pode também ser aplicada a João Antônio. Suas inúmeras cartas acabam constituindo um diário, cujos textos memorialísticos encontram-se espalhados entre diversos interlocutores e que, agora, começam a ser sistematizados. ${ }^{3}$ Sabemos que o diário, a autobiografia, o romance autobiográfico, o autorretrato e a epistolografia são gêneros de natureza diferenciada no conjunto das "escritas de si" Entretanto, na coleção de cartas trocadas entre João Antônio e Jácomo Mandatto, estes gêneros em dados momentos se entrecruzam, uma vez que o discurso vai se moldando de acordo com as estratégias textuais dos interlocutores.

Maria Luiza Ritzel Remédios, ao tratar da dificuldade de diferenciação entre alguns gêneros da "escrita de si", assevera:

2 Apud SOUZA, Luana Soares de. "O eu desconstruído em Conta-corrente, de Virgílio Ferreira". In: REMÉDIOS, Maria Luiza Ritzel (Org). Literatura confessional: autobiografia e ficcionalidade. Porto Alegre: Mercado Aberto, 1997, p. 133.

3 Duas coletâneas de cartas do autor foram organizadas em 2005. São elas: ANTÔNIO, João. Cartas aos amigos Caio Porfirio Carneiro e Fábio Lucas. GIORDANO, Cláudio (Org.). Cotia: Ateliê Editorial, 2005; SEVERIANO, Mylton Paixão de João Antônio. São Paulo: Casa Amarela, 2005. 
Considerando a frágil delimitação entre romance autobiográfico e autobiografia e observando que essa última pode ser considerada como ato literário e, daí, ficcional, observa-se quão difícil se torna também delimitar, na literatura confessional, as fronteiras entre autobiografia e diário íntimo, ou entre autobiografia e autorretrato, ou ainda entre autobiografia e memórias. ${ }^{4}$

O que nos leva a pensar a correspondência entre João Antônio e Jácomo Mandatto como algo situado entre o diário íntimo e a autobiografia é que ela apresenta características tanto de uma quanto de outra expressão memorialística, dando significado, na prática, à própria dificuldade de delimitação dos gêneros testemunhais acima verificada pela ensaísta.

Aqui, a escrita introspectiva do diário e aquela que busca um interlocutor para a narrativa de suas memórias aproximam-se - isso se pensarmos o conjunto da correspondência - da produção da carta, a qual descarta a possibilidade de outros leitores, além do interlocutor imediato.

Um exemplo paradigmático de como se dá o processo de aproximação de gêneros discursivos pode ser observado na carta de João Antônio enviada em 1963 a mais de um de seus correspondentes, e que mais de duas décadas depois foi publicada, no livro Abraçado ao meu rancor, como um conto. Trata-se de "Uma força", o qual tendo sofrido pequenas alterações em sua forma original (mensagem epistolar) para ganhar o estatuto de ficção, não perdeu a essência daquilo que "informava" na carta. Esta, pela forma, em nada difere de uma carta comum; contudo, tanto o conteúdo quanto o trabalho empregado na linguagem causam certa estranheza numa primeira leitura, pois apresentam um trabalho linguístico bastante apurado. A todo momento a linguagem chama mais atenção para si própria do que para o enredo, o que nos remete àquele efeito de estranhamento que, segundo Jakobson, diferencia a linguagem literária das outras.

Assim João Antônio inicia a carta:

4 REMÉDIOS, Maria Luiza Ritzel. Literatura confessional: espaço autobiográfico. In: REMÉDIOS, Maria Luiza Ritzel (Org.) Literatura Confessional: autobiografia e ficcionalidade. Ed. cit., p. 13. 
São Paulo, 25 de março de 1963

Jácomo Mandatto, meu faixa:

Deu-se ontem e de repente e se eu quisesse imitar Clarice Lispector, diria: era um cágado de domingo.

Aconteceu-me um cágado.

Eu andava nas minhas marchas por aí e como me houvessem esquentado a cabeça com aporrinhações domésticas e rusgas profissionais, dinheiro que deveria haver mais, apresentações e cuidados de que não cuido, eu andava por aí.

Acabei, como sempre, pelos subúrbios mais distantes. Lá, Jácomo, longe-longe das minhas chateaçōes.

Uma carta semelhante a essa foi enviada à poetisa Ilka Brunhilde Laurito. Nela observa-se apenas a mudança de interlocutor e de outros dados pontuais. Esse fato suscita a reflexão sobre a natureza da correspondência de João Antônio. Ao enviar exatamente a mesma missiva para amigos diferentes, o escritor acaba por anular o princípio de que a correspondência é o diálogo entre duas pessoas, ou seja, de que uma carta é escrita para um interlocutor particular, sendo os demais leitores descartados desse processo.

Aqui, tal qual num texto autobiográfico, João Antônio quer narrar a sua história para mais de um interlocutor. Envia, então, o texto como se fosse uma carta comum em que conta uma história também comum. Dessa forma, o interlocutor é importante apenas no ambiente da correspondência, uma vez que na forma conto este acabou sendo suprimido: já não se fazia necessário, afinal todos eram interlocutores em potencial. Assim, é possível observar que, se retirarmos aquele a quem o discurso se destina, teremos um texto que se aproxima bastante de uma prosa introspectiva, como aquela que se observa no diário íntimo.

Nesse ponto, mais uma vez, chegamos à questão da carta enquanto suporte literário. Além dessas características mais formais com relação ao cruzamento de gêneros da escrita de si, há ainda o aspecto estético que se coloca bastante premente nessa carta. Já no trecho citado, podemos observar um diálogo com o conto "Uma galinha" (Laços de família), de Clarice Lispector, por meio do uso da expressão 
"cágado de domingo", que no texto da autora aparece como "galinha de domingo", logo na frase que abre a narrativa. ${ }^{5}$

Sobre a possibilidade de uma carta apresentar traços de literariedade, Sophia Angelides sinaliza:

Embora numa carta a descrição de uma paisagem, o relato de um acontecimento, de uma vivência, a expressão de um sentimento tenham o cunho de veracidade, da não-ficçāo, porque seu sujeito-de-enunciação é histórico, o material linguístico é submetido ao crivo altamente seletivo do escritor, que recria a sua experiência pessoal. A este propósito, Jakobson lembra, oportunamente, que o ator, ao retirar a máscara, mostra sua maquilagem. ${ }^{6}$

Na carta em questão, nem sequer sabemos se a história do cágado realmente aconteceu. A este respeito, Jácomo e João Antônio falam ainda outras duas vezes em cartas futuras: como o amigo pergunta sobre o réptil, João Antônio responde que ele havia fugido. $\mathrm{O}$ assunto só volta à tona mais de vinte anos depois, quando o texto é publicado no jornal $O$ Estado de S. Paulo e, em seguida, na coletânea do escritor. Portanto, nos estudos de epistolografia sobrepõe-se à "verdade do fatos" o interesse pelo "registro" em si, como ensina Ângela de Castro Gomes:

está descartada a priori qualquer possibilidade de saber "o que realmente aconteceu" (a verdade dos fatos), pois não é essa a perspectiva do registro feito. O que passa a importar para o historiador é exatamente a ótica assumida pelo registro e como seu autor diz que viu, sentiu e experimentou, retrospectivamente, em relação ao acontecimento. ${ }^{7}$

Uma das leituras possíveis para a carta-conto de João Antônio é, segundo pensamos, a de que se trata de um texto metalinguístico. Sob essa perspectiva, o escritor

5 Na carta dirigida a Ilka Brunhilde Laurito, em 25 de março de 1963, João Antônio escreve: "Deu-se ontem e de repente e se eu quisesse imitar Clarice Lispector, diria: era um cágado de domingo". In: LAURITO, Ilka Brunhilde. João Antônio, o inédito. Remate de Males (Campinas), 19. Universidade Estadual de Campinas Instituto de Estudos da Linguagem. Revista do Departamento de Teoria Literária, 1999.

6 ANGELIDES. Sophia. Carta e literatura: correspondência entre Tchékhov e Górki. São Paulo: Edusp, 2002. p. 23.

7 GOMES, Ângela de Castro. "Escrita de si, escrita da história: a título de prólogo." In: GOMES, A.C. (org.). Escrita de si, escrita da história. Rio de Janeiro: Editora FGV, 2004, p. 15. 
estaria discutindo no texto o próprio fazer literário, tal qual o faz em "Afinação da arte de chutar tampinhas" (Malagueta, Perus e Bacanaço), cujo narrador, em meio à inadequação de sua vida, dedica-se a criar uma arte de chutar tampinhas que encontra pela rua. Assim como as "tampinhas" podem ser vistas como metáforas para "palavras" e, portanto, os "chutes", para a arte narrativa, cremos que o cágado e a ternura que provoca no narrador também podem simbolizar o apego do escritor pela literatura.

Assim, na solidão de homem desenhada na carta-conto, o narrador encontra na palavra a sua companhia perfeita, porque "transcendental":

havia e há entre nós um liame que se prende a coisas tremendamente transcendentais: o calor que sofríamos na subida longa de Vila Ipojuca, aqueles nossos ares de solidão, a chateação comum: a minha de homem, a dele de réptil semiterrestre. Sós e andarilhos, cágado e eu.

Nesse caso, a exemplo do conto "Afinação da arte de chutar tampinhas", a palavra e, por conseguinte, quem dela se enamora são também marginalizados, uma vez que não se enquadram entre os valores dominantes em nossa sociedade. Naquele conto, vemos o protagonista se esmerando em seus chutes, enquanto seu irmão desfecha: "Você é um largado. Onde se viu essa agora!"

$\mathrm{Na}$ carta, a família também aparece como elemento de incompreensão, afinal "tiveram medo do cágado. Ou quase"; os familiares ainda se lembram de sugerir um nome de imperador para batizar o humilde animal. Aí surge mais uma vez a afirmação da escolha do escritor (que nesse caso coincide com a do narrador) pelas "criaturas e viventes que se mexam com humildade, que tenham tolerância, humanas e boas como o cágado". Ou seja, é possível pensar que, com isso, o autor esteja negando a grandiloquência de certo ramo literário, enquanto reafirma a linguagem recriada a partir de suas vivências da rua.

No trecho a seguir - "Sei que ele próprio carrega a sua casa nele mesmo. Tolice pretender a construção de uma casa aquática ou terrestre. Mas sou um egoísta, gostei dele, quero que fique comigo. Que faça aquele silêncio seu de persistência e sabe-

8 ANTÔNIO, João. Malagueta, Perus e Bacanaço. São Paulo: Cosac Naify, 2004, p. 42. 
doria", talvez pudéssemos pensar que há uma certa resignação do escritor frente à impossibilidade de traçar um caminho para suas criaturas, já que estas, alheias aos desejos de seu criador, acabam por seguir o destino dado a elas pelos leitores. Há, ainda, nesse excerto, algumas construções linguísticas dignas de nota. Quando diz "quero que fique comigo", notamos que o modo como utiliza os fonemas imprime certa dureza à frase. Ouvimos quase um bater de pés, algo entre uma birra e uma imposição. Entretanto, tal dureza é amenizada pela frase seguinte - "Que faça aquele silêncio seu de persistência e sabedoria" -, em que a repetição de fricativas provoca uma alteração cujo efeito é de leveza, algo como um deslizar, o que está em total consonância com o silêncio invocado pelo narrador.

Vejamos, a seguir, o trecho em que explica o porquê de contar ou não os episódios narrados:

Eu lhe conto essas coisas, Jácomo, da condição de um cágado e da minha condição, porque você é Jácomo Mandatto, um sujeito bom e munido de antenas. Só a sujeitos assim eu conto. Porque há coisas a dizer que estão muito além do arroz com feijão de cada dia, da alta ou queda do dólar.

Nota-se que, para se estabelecer o diálogo, esse alguém colocado do outro lado deve ser "munido de antenas" Isso equivale a dizer que o leitor precisa "entender" ou estar disposto a entender as coisas "que estão muito além do arroz com feijão de cada dia". O narrador parece dizer-se consciente de que seu texto, provavelmente, será incompreendido, afinal poucos o lerão em profundidade.

Adiante, a relação estabelecida entre os cuidados que toma com o réptil e o trabalho de criação artística aparece ainda mais explícita:

Telefonei ao Butantã, tomei conselhos com amigos, indaguei, agora sei que meu cágado é um cágado e não é jabuti. Um cágado-de-pescoço-de-cobra.

E é, Jácomo, como se fosse um filho. Tem dado cada susto, Jácomo, é como se fosse um amor.

Um sentimento indefinido me une ao réptil cágado, um querer bem, um querer tomar conta, fazer bem, não deixar faltar nada. Que é que sei... 
É possível notar logo no início o trabalho que o narrador despende em busca do termo correto para designar o animal. Depois de toda a pesquisa, afirma, por meio da junção de cinco palavras, que este é "um cágado-de-pescoço-de-cobra", criando um efeito visual bastante curioso, fazendo do vocábulo construído a imagem do próprio pescoço do animal.

Em "E é, Jácomo, como se fosse um filho. Tem dado cada susto", há algo da afirmação constante de que suas personagens seriam seus filhos. E adiante, "Jácomo, é como se fosse um amor" cria um efeito análogo a este expresso anteriormente, já que a literatura é sua grande paixão, tal qual diria metaforicamente em seu único poema, "Choros - para Pintagol e Cuíca": "a [mulher] que eu não tenho / é quem requebra só pra mim / e quando acorda me entreolha e diz / se ainda durmo, vida, ficaste mais linda".

Ao final da carta temos uma espécie de prece: "Peço ao Senhor das esferas, não ao Deus fantasiado, esculpido ou rezado das igrejas, mas a um Deus de consciência cósmica, eu peço, Jácomo. Só faz um dia... Mas que o cágado não morra antes de mim". Aqui talvez pudéssemos interpretar como um desejo de perenidade, de que seus textos conseguissem sobreviver até muito depois de sua morte.

Outro elemento que merece ser citado - agora mais com relação à versão publicada em livro de contos - é que, em "Uma força", João Antônio inseriu a personagem Aldônia, que figura como uma espécie de amor juvenil do narrador. O interessante disso é que no conto "Afinação da arte de chutar tampinhas" temos também uma Aldônia. Esta, entretanto, surge na cabeça do narrador, que aparenta não ser mais tão jovem como o da outra narrativa, como uma lembrança ruim: "Engraçado - Aldônia até hoje não presta".'0

Com relação ao imbricamento entre construção memorialística e literária, há outros trechos da correspondência que são emblemáticos. Seja em seus textos de caráter mais pessoal, como por exemplo em seu autorretrato, "De Malagueta, Perus e Bacanaço"," seja em sua literatura propriamente dita, vê-se certo esforço

\footnotetext{
9 ANTÔNIO, João apud SEVERIANO, Mylton. Paixāo de Joāo Antônio. São Paulo: Casa Amarela, 2005, p. 89. 10 ANTÔNIO, João. Malagueta, Perus e Bacanaço. Ed. cit., p. 40.

11 Texto publicado em vários órgăos de imprensa à época da edição de Malagueta, Perus e Bacanaço; na edição da obra feita pela editora Círculo do Livro, na década de oitenta, e, finalmente, na edição preparada pela editora Cosac Naify, referenciada acima.
} 
por parte de João Antônio em ratificar o imaginário de escritor boêmio, com total aderência às suas personagens. Este empenho foi quase totalmente recompensado, uma vez que poucos foram os analistas de sua obra que conseguiram falar dela sem remeter, ainda que por derivação, à sua experiência de vida.

Se esse entrecruzamento entre vida e obra se dá tão fortemente na literatura joãoantoniana a ponto de parte da crítica ter sido levada pelo canto da sereia, na correspondência esse canto fica ainda mais forte. Nela, tudo é potencialmente verdadeiro, uma vez que aquele é o espaço da confissão e dos desvelamentos do eu.

É aí, nesse espaço confessional, que João Antônio mais uma vez se recria, torna-se persona e ficcionaliza a sua memória, com a diferença de que isso não se dá de maneira retrospectiva, como quando um autor escreve a sua autobiografia e faz a seleção ora consciente ora inconsciente daquilo que deseja que conste de seu memorial. Aqui, temos um autor que escreve suas memórias no calor da hora, pois a consciência da posteridade o faz tornar-se persona, algo entre a pessoa real e as suas diversas personagens literárias.

Em estudo anteriormente citado, Sophia Angelides trata dessa fusão "entre a personalidade literária e a humana" no escritor russo Máximo Górki. A autora analisa uma carta e afirma que esta

é, sem dúvida, um documento, um depoimento, mas é sobretudo um trecho muito gorkiano. Ao expor os sentimentos que Tio Vânia suscitou, volta-se para si mesmo, exprimindo-se de maneira exuberante e emotiva, numa linguagem adornada de comparações, digressões e imagens, o que é característico de grande parte de sua obra literária. Convém ainda lembrar que os escritos de Górki são marcados pelo elemento autobiográfico. Daí decorre que parece haver, frequentemente, uma fusão muito direta entre a personalidade literária e a humana. ${ }^{22}$

Vejamos, pois, exemplos dessa fusão nas cartas de João Antônio a Mandatto. Em carta de 24 de maio de 1963 , ele fala sobre sua solidão e sobre como a literatura o afeta:

12 ANGELIDES. Sophia. Op. cit., p. 25.

Teresa revista de Literatura Brasileira [8|9]; São Paulo, p. 356-371, 2008. • 367 
Eu deveria estar arrasado por dentro e não estou. A literatura, Jácomo, tem todas as funções que você deseje determinar. Sobre mim, solitário e dracular Jácomo, este fato extraordinário funciona inteiramente. Terapêutica, forma estranha de vingança e reconstrução, cópula mental, namoro comigo mesmo, luz, fonte, martírio e insatisfação também. Seriam necessários muitos adjetivos, advérbios, substantivos e verbos para esclarecer o que se passa comigo diante da literatura. Jácomo, ela me arranca do caos. Puxa-me pelos cabelos, pelas pernas, pelas ventas. Como naquele diálogo imenso (e de tão poucas palavras) que Emanuelle Riva repete: "Tu me matas. Tu me consolas". Assim. Como em "Hiroshima, mon amour"13

Neste excerto, o tom inicial é de diálogo, mas já apresenta algo de ensaístico, pois propõe uma reflexão sobre as funções da literatura. A seguir, um certo lirismo vai contaminando o texto, até que, ao final, não conseguimos escapar à sensação de ter lido um poema.

O uso de paradoxos, aliado a uma pontuação que se faz expressiva por meio do recurso da gradação, permite ao leitor experimentar a sensação de integralidade proposta pelo autor. Vamos, num crescendo, sendo inundados por aquele sentir que, longe da linearidade, apresenta-se por meio de termos usualmente antitéticos, mas que aqui são primordiais na construção do todo: "Terapêutica, forma estranha de vingança e reconstrução, cópula mental, namoro comigo mesmo, luz, fonte, martírio e insatisfação também". Nota-se ainda que o escritor não usou um único verbo na construção desse período, o que faz com que este esteja totalmente subordinado, tanto ao que o antecede quanto àquele que o sucede.

A seguir, ele desfecha: "Seriam necessários muitos adjetivos, advérbios, substantivos e verbos para esclarecer o que se passa comigo diante da literatura". Vemos aí que o escritor emprega o verbo "ser" no futuro do pretérito, o que indica, em certa medida, uma necessidade cuja perspectiva de resolução é pequena, já que esta se encontra num tempo intermediário entre futuro e passado.

Por fim, João Antônio tenta novamente definir a sua relação com a literatura. Outra vez, temos o jogo de paradoxos, pois ao mesmo tempo em que diz "ela me arranca do caos", o que remete a uma situação de calmaria, também afirma que a literatura

13 Carta de 24 maio 1963. 
o puxa "pelos cabelos, pelas pernas, pelas ventas" imagem que alude mais a uma luta do que à tranquilidade expressa anteriormente. Ao final do excerto, notamos que esses paradoxos são ainda mais reafirmados por meio de construções como "diálogo imenso e (de tão poucas palavras)" e "Tu me matas. Tu me consolas"

Podemos ver nesse trecho um exemplo do tom ensaístico cultivado por João Antônio em sua correspondência com Mandatto, uma vez que temos um texto buscando teorizar sobre a função e os efeitos da literatura na vida do autor, sendo que, em certa medida, este parece figurar ali também como símbolo dos aficionados por aquela arte e não simplesmente representando a si próprio.

Há ainda outro trecho dessa mesma missiva ${ }^{14}$ que vale ser citado. Trata-se de um longo parágrafo em que o escritor descreve o processo de produção de um romance que vinha escrevendo sobre o universo da propaganda ${ }^{15}$ :

Ah, Jácomo, mas há a imensa arraia miúda da propaganda se misturando aos ricos da propaganda! Gloriosos e vitoriosos, canalhas e sorridentes, desfilarão os donos de agências com suas residências na Avenida Nove de Julho, no Brooklin, suas ostentações. A miséria humana, a incomunicação, a solidão de um artista, as banhas dos diretores, a verminose eloquente que anda na cara dos meninos entregadores de coisas, as briguinhas por causa de cinquenta mil réis. A exdruxularia passeando. Os melhores cobradores são sempre péssimos pagadores. O sentimento de menos valia que envolve o artista, sua errada verificação de uma falência que nada tem a ver com ele mesmo. O homem torcido, os canalhas sempre marchando para uma vitória. A modelo prostituída, os homens, as máquinas de escrever, o telefone. A menina do telefone. O pintor de painéis lá está no ar, pendurado a uma corda, dando a vida a troco de... De pão. São homens sem direito, sem eira nem beira. Um malandro diria:

- Esses caras aí estão numa merda que faz gosto.

Em princípio, tal qual no excerto anterior, temos um diálogo que passa a um matiz ensaístico, para, em seguida, adquirir um tom bastante poético. Nota-se que o

14 Carta de 24 maio 1963

15 Trata-se de "Irmãos Raccatti Ltda., texto no qual o autor passou parte do ano de 1963 trabalhando, mas que nunca chegou a publicar. 
parágrafo é construído basicamente pelo processo de enumeração, cuja pontuação obedece a uma sequência bastante curiosa, já que não há quase a recorrência de conjunções subordinativas ou coordenativas. Assim, têm-se basicamente períodos assindéticos; construção que, segundo Jane Christina Pereira, por aproximar-se da linguagem oral, "possui um tom mais espontâneo, menos rigor lógico; é mais ágil, sugere a simultaneidade ou a rápida sequência dos fatos".16

É interessante observar aí também a caracterização dos personagens. Os chefes e donos das agências, "canalhas e sorridentes", são apresentados com grande desprezo, enquanto a "arraia miúda", representada pelos "artistas" "modelo prostituída", "pintor de painéis", "menina do telefone", "meninos entregadores de coisas" etc., surge de forma a provocar forte sentimento de ternura no leitor. Temos, pois, a mesma defesa que seria expressa posteriormente no ensaio "Corpo-a-corpo com a vida": a de que o escritor deve olhar à própria volta e colocar-se a serviço dos sem eira nem beira.

Com relação ao aspecto geral do parágrafo, João Antônio conseguiu construir um quadro em que o leitor é apresentado àquele universo narrado. É como se víssemos uma cena, algo como uma peça de propaganda, cuja agilidade dramática nos conquista. Isto se dá por conta daquele aspecto da união entre linguagem oral e construção assindética das frases, discutido anteriormente, mas também por meio do uso constante de verbos no presente do indicativo e no gerúndio. O trecho final, "O pintor de painéis lá está no ar, pendurado a uma corda, dando a vida a troco de... De pão", é um exemplo cabal dessa construção. Nessa frase, o contista parece erguer o braço e apontar para o pintor de painéis, pois a cena é construída com vigor cinematográfico, impondo-nos a visão do trabalhador balançando na corda que o sustenta. A propósito, o excerto apresenta os fonemas " $d$ " e " $p$ " repetidos ostensivamente, o que produz um efeito de pêndulo proposto pela frase. Nesses, como em outros trechos da correspondência joão-antoniana, o contista fala de si por meio do outro. Aqui, temos uma categoria diferente de memória, uma vez que o autor quase se esconde atrás de suas personagens. Entretanto, pode-se pensar que esta é uma forma de cortejar a eternidade, já que ele sabe que

16 PEREIRA, Jane Christina. A poesia de Malagueta, Perus e Bacanaço. Assis, 2006. Tese (Doutorado em Letras) Universidade Estadual Paulista, p. 105.

370 - OLIVEIRA, Ana Maria Domingues de; SILVA, Telma Maciel da. Memória e ficção... 
deixar-se escrito é a única maneira de escapar à morte. Assim, João Antônio fala de sua experiência no mundo da publicidade, mas faz dela uma história maior do que suas vivências, faz dela uma experiência literária. Também a relação do escritor com a literatura é igualmente fonte para a construção estética, uma vez que suas reflexões acerca do ofício literário são mediadas pelo trabalho linguístico apurado, que nasce de sua profunda consciência da palavra.

Ana Maria Domingues de Oliveira é doutora em Letras pela Universidade de São Paulo. Docente na UNESP, campus de Assis, desde 1991, ali coordena o Acervo João Antônio. Autora do livro Estudo crítico da bibliografia sobre Cecília Meireles.

Telma Maciel da Silva é doutoranda do programa de pós-graduação em Letras da UNESP de Assis, bolsista da FAPESP. Participa da equipe de pesquisadores do Acervo João Antônio. 